\title{
Investigating the factor structure of the South African Personality Inventory - English version
}

\begin{tabular}{|c|c|}
\hline \multicolumn{2}{|c|}{$\begin{array}{l}\text { Authors: } \\
\text { Nadia Morton }{ }^{1} \text { (D) } \\
\text { Carin Hill }{ }^{1} \text { (D) } \\
\text { Deon Meiring } \\
{\text { Leon T. de } \text { Beer }^{3}}^{\text {(D) }}\end{array}$} \\
\hline \multicolumn{2}{|c|}{$\begin{array}{l}\text { Affiliations: } \\
{ }^{1} \text { Department of Industrial } \\
\text { Psychology and People } \\
\text { Management, University of } \\
\text { Johannesburg, Johannesburg. } \\
\text { South Africa }\end{array}$} \\
\hline \multicolumn{2}{|c|}{$\begin{array}{l}{ }^{2} \text { Department of Human } \\
\text { Resource Management, } \\
\text { University of Pretoria, } \\
\text { Pretoria, South Africa }\end{array}$} \\
\hline \multicolumn{2}{|c|}{$\begin{array}{l}{ }^{3} \text { WorkWell Research Unit, } \\
\text { North-West University, } \\
\text { Potchefstroom, South Africa }\end{array}$} \\
\hline \multicolumn{2}{|c|}{$\begin{array}{l}\text { Corresponding author: } \\
\text { Carin Hill, } \\
\text { chill@uj.ac.za }\end{array}$} \\
\hline \multicolumn{2}{|c|}{$\begin{array}{l}\text { Dates: } \\
\text { Received: } 30 \text { May } 2018 \\
\text { Accepted: } 21 \text { July } 2019 \\
\text { Published: } 17 \text { Oct. } 2019\end{array}$} \\
\hline \multicolumn{2}{|c|}{$\begin{array}{l}\text { How to cite this article: } \\
\text { Morton, N., Hill, C., Meiring, D., } \\
\text { \& De Beer, L.T. (2019). } \\
\text { Investigating the factor } \\
\text { structure of the South African } \\
\text { Personality Inventory - } \\
\text { English version. SA Journal } \\
\text { of Industrial Psychology/SA } \\
\text { Tydskrif vir Bedryfsielkunde, } \\
45(0) \text {, a1556. https://doi.org/ } \\
\text { 10.4102/sajip.v45i0.1556 }\end{array}$} \\
\hline \multicolumn{2}{|c|}{$\begin{array}{l}\text { Copyright: } \\
\text { C 2019. The Authors } \\
\text { Licensee: AOSIS. This } \\
\text { is licensed under the } \\
\text { Creative Commons } \\
\text { Attribution License. }\end{array}$} \\
\hline \multicolumn{2}{|l|}{ Read online: } \\
\hline 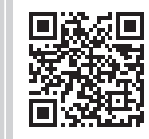 & $\begin{array}{l}\text { Scan this QR } \\
\text { code with your } \\
\text { smart phone or } \\
\text { mobile device } \\
\text { to read online. }\end{array}$ \\
\hline
\end{tabular}

Orientation: Most psychological measuring instruments developed in Western, educated, industrial, rich, democratic (W.E.I.R.D.) countries have been found to inadequately capture and represent personality outside the borders of these countries. Consequently, culturally informed or indigenous measuring instruments need to be developed.

Research purpose: This study aimed to inspect whether an overlap exists between the empirical data obtained and the theoretical six-factor SAPI framework, providing evidence for an indigenous personality structure in a multi-cultural context.

Motivation for the study: Psychological professionals in South Africa have been criticised for using culturally biased instruments that do not display an accurate representation of the 11 official cultural groups. The South African Personality Inventory (SAPI) aims to address these criticisms, highlighting the importance of establishing the cultural applicability of the model through model-fit analyses.

Research approach/design and method: A quantitative, cross-sectional design was used to administer the SAPI-English version to a sample of employed, unemployed and employmentseeking South Africans $(N=3912)$. Exploratory Structural Equation Modelling (ESEM) was used to model the data.

Main findings: The results revealed that the model was a good fit to the data and that the SAPI factors accurately represent personality in a multi-cultural context.

Practical/managerial implication: Using a well-researched indigenous personality assessment like the SAPI can assist South African organisations to fairly and reliably assess people across the 11 official cultural groups.

Contribution/value-add: This study advances the processes surrounding indigenous test development through the establishment of a personality model and measure that encapsulates personality traits exhibited in a multi-cultural context.

Keywords: Personality; South African Personality Inventory; SAPI; factor structure; assessment; South Africa.

\section{Introduction}

In the fields of psychological testing and assessment, research has reached many difficult-to-attain goals (Laher \& Cockroft, 2014). However, most psychological tests and assessments stemming from research conducted in Western, educated, industrial, rich, democratic (W.E.I.R.D.) countries fail to acknowledge psychological principles in non-W.E.I.R.D. contexts (Henrich, Heine, \& Norenzayan, 2010). In the South African context, many psychological tests and assessments have been criticised for inadequately capturing and representing cultures outside the countries of origin, mainly in Europe and North America (Blokland, 2016), especially because individuals within a multi-cultural context such as South Africa have traditions and beliefs that are quite distinct from those found in Europe and America (Moletsane, 2016). These cultural differences also influence how individuals perceive personality and exhibit behaviours related to it. As such, personality assessment within the South African context has shifted focus from studying mainly universal traits across cultures to also studying personality traits specific or unique within various cultures (cf. Valchev et al., 2011; Valchev et al., 2012; Valchev, Van de Vijver, Nel, Rothmann, \& Meiring, 2013; Valchev et al., 2014) using an emic-etic approach. The emic-etic, a combined approach, outlines universal and culture-specific aspects of personality (Cheung 2012; Cheung, Van de Vijver, \& Leong, 2011) to identify critical aspects pertaining to personality (in South Africa in this case) and attain a detailed, integrated and balanced view of personality (Cheung et al., 2011). 


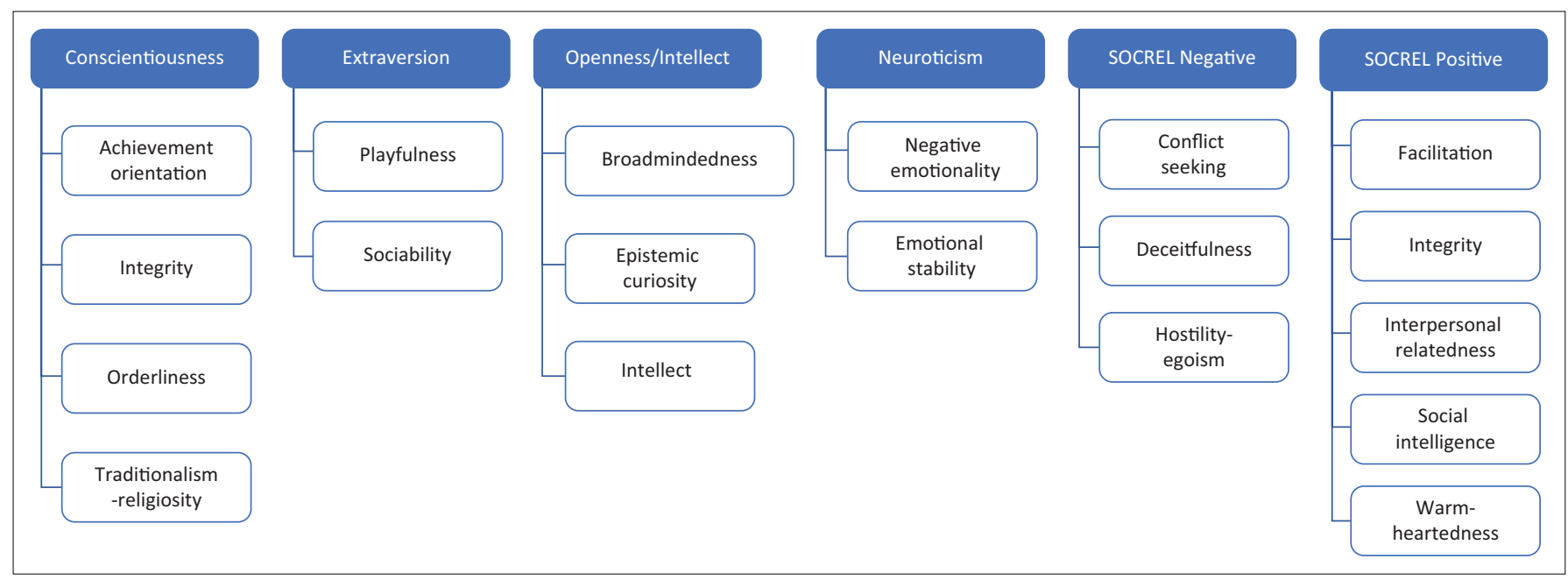

FIGURE 1: Schematic representation of the six-dimensional structure and accompanying facets of the South African Personality Inventory as identified by Fetvadjiev et al. (2015).

In the South African context, personality research has mostly followed international trends, using adapted existing models and measuring instruments (Valchev et al., 2011; Valchev et al., 2012). However, in the early 1990s, the South African Personality Questionnaire (SAPQ) (Taylor, 1987) was developed, in which researchers attempted to develop an instrument that captures the personality characteristics evident in South Africa's multi-cultural context. Unfortunately, the SAPQ did not succeed, with a few studies investigating and confirming bias within the measurement (Retief, 1992; Taylor \& Boeyens, 1991). The existence of bias could be ascribed to overreliance on Western and European models and theories. The adapted measuring instruments did not adequately tap into the underlying personality constructs within the cultural groups found in South Africa (Van de Vijver \& Leung, 2001), raising questions surrounding fairness in assessment in the South African context.

Another matter influencing the South African psychological assessment landscape is South African legislation. The Employment Equity Act 55 of 1998 (Republic of South Africa, 1998) emphasises the use of valid, reliable and fair assessments and tests as a means to eliminate unfair discrimination, promote affirmative action and redress any previous disadvantages individuals from minority groups might have experienced. The requirements stipulated in the Employment Equity Act provide a framework and guideline for researchers aiming to develop and publish psychological measuring instruments, by emphasising the importance of fairness and cross-cultural application within psychological testing and assessment.

\section{South African Personality Inventory}

To address the issues surrounding valid, reliable and fair assessment in a multi-cultural context, the South African Personality Inventory (SAPI) project was initiated, aimed to develop a personality model and instrument that is applicable to the various cultural and language groups evident in South Africa (Hill et al., 2013; Nel, 2008). The commencement of the SAPI project assisted in deriving authentic, culturally relevant and accurate personalitydescriptive terms from each of the 11 official languages in South Africa (Nel, 2008), involving both a qualitative and a quantitative phase. ${ }^{1}$

The SAPI was initially represented by a qualitatively identified nine-factor structure, such as conscientiousness, emotional stability, extraversion, facilitation, integrity, intellect, openness, relationship harmony and soft-heartedness (Nel, 2008). Validation studies conducted on the preliminary SAPI proved that each of the initial nine clusters mentioned above was relevant to the linguistic and cultural groups found in South Africa (Valchev et al., 2014).

However, a more recent quantitative study by Fetvadjiev, Meiring, Van de Vijver, Nel, and Hill (2015) proposed that the SAPI personality model works best with six factors, such as conscientiousness, extraversion, neuroticism, openness, positive social-relational disposition and negative socialrelational disposition. Within Fetvadjiev and colleagues' (2015) study, 18 facet scales (see Figure 1) representing the SAPI were used with a combination of 146 items that were based on the per-cluster factor analysis conducted in the last stage of item selection of the project. The conscientiousness, extraversion, neuroticism and openness factors of the SAPI are similar to those of the Big Five, with the positive and negative social-relational disposition being unique to the SAPI (Fetvadjiev et al., 2015) and personality in the South African context. To date, no studies have been conducted to confirm this six-factor SAPI structure.

Therefore, the purpose of this study was to explore the extent to which the six-factor SAPI model fits the data, using two different factor analytical techniques, such as confirmatory factor analysis (CFA) and ESEM.

1.The qualitative and quantitative process outlined in this article provides only an overview of the progress to date and a full description of the phases can be found in Fetvadjiev et al. (2015); Hill et al. (2013); Nel (2008); Nel at al. (2015); and Valchev (2011, 2012, 2013). 


\section{Analysing the factor structure of the South African Personality Inventory}

Fetvadjiev and colleagues (2015) reduced the initial SAPI item pool from 2574 to 146 items and subsequently extracted the six-factor structure with its accompanying facets using exploratory factor analysis (EFA). Cronbach's alpha coefficients for the facets ranged between 0.60 and 0.84 , except for the deceitfulness (0.58) and traditional-religiosity (0.57) facets whose low reliability coefficients were most likely because of the facets comprising three and four items, respectively. Fetvadjiev et al. (2015) also investigated the correlations between the various SAPI factors, and found that '...there may be a common element of presumably normdriven, effortful self-regulation that underlies variation both of conscientiousness in endeavour-related contexts and of SR-Positive in interpersonal context...' (p. 830). Thereafter the equivalence of the factor structure across the African, mixed race, Indian and white ethnic groups was assessed, and it was found that 19 of the 24 Tucker's $\varphi$ congruence coefficients were above 0.95 , indicating structure equivalence. Lastly, Fetvadjiev et al. (2015) used an independent sample of African and white students to assess the six-factor solution's stability and subsequently replicated the factor structure reasonably well.

Mouton (2017) conducted a study aimed at understanding the dimensionality and model fit of both the first- and second-order SAPI models, using the LISREL statistical software package adopting a CFA analysis method. The dimensionality was analysed by subjecting each of the 20 personality subscales in the SAPI to an unrestricted principal axis factor analysis with oblique rotation. Mouton (2017) found that most of the test items do reflect the corresponding latent constructs (facets), as depicted in the theoretical framework developed during the qualitative phase. In addition, the first-order model (six factors and 20 facets) was found to fit the broader society of South Africa very well. However, the model fit of the second-order model could not be computed and evaluated, as the model did not converge successfully and as such produced inadmissible results (see Mouton, 2017).

Confirmatory factor analysis would generally be the approach of choice to confirm an empirically proposed personality model such as the SAPI. It provides researchers with the opportunity to draw direct comparisons between alternative models of relationships (Strauss \& Smith, 2009) and to analyse relationships between latent constructs (Marsh, Morin, Parker, \& Kaur, 2014). However, reliable psychological models are unfit when researchers evaluated them using CFA (Marsh et al., 2014; McCrae, 1996; Xiao, Liu, \& Hua, 2019). The strict requirement of zero cross-loadings in CFA forces researchers to assume a parsimonious model that does not always provide sufficient support for a psychological construct that has previously been identified and established via EFA (Asparouhov \& Muthén, 2009; Marsh et al., 2014).
Specifically, within personality research, CFA has been found to provide insufficient support for standard measures such as the Five Factor Model (FFM), leading researchers to believe that such measures did not adequately fit the data (Marsh, Nagengast, \& Morin, 2013). Asparouhov and Muthén (2009) stated that the restrictions imposed when using CFA could result in researchers developing measuring instruments that have a simple measuring structure. The credibility and replicability of such a measure can subsequently be doubted (Asparouhov \& Muthén, 2009) and a priori structures not being supported by the data (Marsh et al., 2010).

To counter the possible inconsistencies between EFA and CFA models, more recent studies have found that an ESEM could be used to get a more accurate understanding of a confirmed hypothesised model (Asparouhov \& Muthén, 2009; Marsh et al., 2013; Marsh et al., 2014; Morin, \& Marsh, 2010; Xiao et al., 2019). Exploratory structural equation modelling combines the best properties of both EFA and CFA to provide researchers with relations between the latent factors such as personality (Marsh et al., 2014), accurately examine the broad applicability of such complex measurement structures in a cross-cultural context (Asparouhov \& Muthén, 2009; Marsh et al., 2010). Marsh et al. (2014) indicated that ESEM provides a general framework that combines both EFA and CFA procedures, leaving researchers with the 'best of both worlds' in which realistic estimates usually inflated in traditional CFA analyses can be expected. Asparouhov and Muthén (2009) further added that ESEM uses all the structural equation modelling parameters mostly used by researchers and combines it with the factor loading rotations found in EFA. Exploratory structural equation modelling overcomes the restrictions imposed during standard CFA and provides a richer set of $a$ priori models that are more supportive of the hypothesised psychological model in focus (Marsh et al., 2010).

For the current study, CFA was chosen as a starting point within the analysis process because of its simple processes and results. However, the researchers were expecting to find CFA results that indicated the SAPI measurement instrument and model did not accurately represent personality within a multi-cultural context when inspecting the model-fit indices, and that refinements would have to be made to the current model. They anticipated that developing a simple-structure measuring instrument would not be plausible with a multi-dimensional construct such as personality (Church \& Burke, 1994; Marsh et al., 2010) and that a method such as ESEM should be used in second-round validation studies. Exploratory structural equation modelling could answer questions surrounding multi-dimensional models such as personality that are usually left unanswered through traditional EFA and CFA procedures (Marsh et al., 2010).

\section{Objectives}

The primary objective of this study was to examine the model-fit of the SAPI and thus determine whether the SAPI produces results that are per the theoretical and empirically 
determined framework developed to date. The following research questions were investigated:

- Can the six-factor measurement model as suggested by Fetvadjiev et al. (2015) be closely replicated within the current sample?

- Will the cross-loadings of the facets on their designated latent SAPI factors be statistically significant?

- To what extent will the latent SAPI factors correlate with each other?

- Will the reliabilities of the latent SAPI factors be acceptable?

\section{Research design Research approach}

A cross-sectional, quantitative research design was used to transform the information obtained into numerical terms for statistical purposes (Marshall, 1996) and to enhance the communication of the multi-dimensional results (Netemeyer, Bearden, \& Sharma, 2003). Also, the quantitative design was further chosen for the researchers to draw a sample demonstrative of the different cultural groups within the South African population that can assist with the understanding of, and generalisation of, the results (Marshall, 1996).

\section{Research method}

\section{Research participants}

Convenience sampling was used between 2015 and 2016 to approach individuals and organisations willing to take part in the research. The participants included tertiary students, job-seekers and working adults from various industries in the South African workforce and at various organisational levels $(N=3912)$ (Table 1$)$.

Table 1 indicates that most of the participants were female (55\%), while more than half of the participants were from the white (33\%) and African (22\%) cultural groups. Many of the participants (33\%) did not indicate the ethnic group to which they belonged and were consequently removed from the analyses. Most of the participants (80\%) matriculated between 1999 and 2014; therefore, the approximate age of that section of the sample ranged between 20 and 44. The majority of the participants had obtained a qualification after leaving school (74\%) and indicated that they had a good English reading ability (78\%). Many applicants worked in industries not mentioned in the biographical questionnaire $(13 \%)$; of those industry options provided, most participants worked within the Information Technology or Computing (9\%) sector, within the Human Resource Management industry $(7 \%)$, or were currently studying $(9 \%)$.

\section{Measuring instrument}

\section{SAPI-188-E}

The English version of the SAPI, based on the newly identified model, was used. Fetvadjiev et al. (2015) found the SAPI to consist of six factors, 18 facets and 146 items $^{2}$ that were rated 2.The instrument is copyright-protected, therefore no verbatim examples of the items are included.
TABLE 1: Characteristics of the participants $(N=3912)$.

\begin{tabular}{|c|c|c|}
\hline Characteristic & $n$ & Percentage \\
\hline \multicolumn{3}{|l|}{ Gender } \\
\hline Male & 1750 & 44.72 \\
\hline Female & 2161 & 55.23 \\
\hline \multicolumn{3}{|l|}{ Ethnicity } \\
\hline African people & 840 & 21.47 \\
\hline Asian people & 5 & 0.13 \\
\hline Mixed-race people & 231 & 5.90 \\
\hline Indian people & 176 & 4.50 \\
\hline White people & 1286 & 32.86 \\
\hline Other & 72 & 1.84 \\
\hline \multicolumn{3}{|c|}{ Year matriculated (approximate age in 2016) } \\
\hline 1960-1969 (65-74) & 146 & 3.37 \\
\hline 1970-1979 (55-64) & 173 & 4.42 \\
\hline $1980-1989(45-54)$ & 478 & 12.22 \\
\hline $1990-1999(35-44)$ & 969 & 24.76 \\
\hline $2000-2009(25-34)$ & 1373 & 35.09 \\
\hline $2010-2014(20-24)$ & 772 & 19.73 \\
\hline \multicolumn{3}{|l|}{ Educational level } \\
\hline School & 892 & 22.80 \\
\hline Post-school & 2907 & 74.29 \\
\hline \multicolumn{3}{|l|}{ English reading ability } \\
\hline Very poor & 115 & 2.94 \\
\hline Poor & 17 & 0.43 \\
\hline Good & 734 & 18.76 \\
\hline Very good & 3046 & 77.84 \\
\hline \multicolumn{3}{|l|}{ Industry } \\
\hline Airlines or Airports & 143 & 3.65 \\
\hline Automobile & 82 & 2.10 \\
\hline Construction & 100 & 2.56 \\
\hline Education & 248 & 6.34 \\
\hline Electric or Engineering & 135 & 3.45 \\
\hline Entertainment or Leisure & 30 & 0.77 \\
\hline Finances & 342 & 8.74 \\
\hline Food and Beverages & 154 & 3.94 \\
\hline Government & 134 & 3.42 \\
\hline Hospitality & 179 & 4.57 \\
\hline Human Resource Management & 279 & 7.13 \\
\hline Information Technology or Computing & 359 & 9.17 \\
\hline Insurance & 75 & 1.92 \\
\hline Legal & 55 & 1.41 \\
\hline Media and/or Publishing & 93 & 2.38 \\
\hline Mining & 118 & 3.02 \\
\hline Oil and Gas & 45 & 1.15 \\
\hline Pharmaceuticals & 34 & 0.87 \\
\hline Professional Services or Consulting & 168 & 4.29 \\
\hline Real Estate & 24 & 0.61 \\
\hline Retail & 136 & 3.48 \\
\hline Student & 357 & 9.12 \\
\hline Telecommunications & 61 & 1.56 \\
\hline Travel or Tourism & 37 & 0.95 \\
\hline Wholesale & 22 & 0.56 \\
\hline Other & 502 & 12.83 \\
\hline
\end{tabular}

on a 5-point Likert-type scale with responses ranging from 1 (strongly disagree) to 5 (strongly agree). Fetvadjiev et al. (2015) calculated the mean reliability of $\alpha=0.77$ for the 18 SAPI facets. Upon reviewing Fetvadjiev's results, the authors elected to include 24 additional items to strengthen the conscientiousness, openness, negative social-relational disposition and positive social-relational disposition factors. 
Two additional facets were added: empathy (positive socialrelational disposition) and arrogance (negative socialrelational disposition). These items were selected from the existing SAPI item bank. The final instrument, therefore, contained 170 items and 20 facets that represented the six SAPI factors and that were randomly placed and administered. The scale also included 18 social-desirability items, specially developed for the SAPI. These items were not included in the data analysis of this study.

\section{Research procedure}

Research participants from various sectors (educational institutions, public and private organisations) and with varying employment statuses (employed, unemployed, seeking employment) were invited to complete an online version of the SAPI voluntarily. Prior to completing the questionnaire, participants were ensured of (1) the aim of the questionnaire (to collect information regarding personality), (2) the secure nature of the data, (3) the lack of psychological risk associated with the study, (4) the confidentiality of the research project and (5) the aggregate use of the data. Participants had to give consent before commencing with the questionnaire. The institution's research ethics committee provided ethical clearance for the study.

\section{Statistical analysis}

To analyse the data and assess the model fit to the data, Mplus Version 8.0 was used (Muthén \& Muthén, 2017). A CFA and an ESEM model were compared. ${ }^{3}$ The initial analyses consisted of a traditional CFA to evaluate the fit of the postulated six-factor model of the SAPI (see Appendix 1 for the CFA input syntax). During CFA, the proposed sixfactor model of the SAPI was fitted to the observed data, using maximum likelihood estimation and allowing the six factors to correlate with each other. The researchers were particularly interested in applying ESEM to the SAPI model. The ESEM approach allows for all the facets in the SAPI to cross-load on all factors in the attempt to determine the potential impact of the facets on the factors that measure personality. Facets were computed using the mean score of the individual items. During the ESEM procedure, the suggested oblique rotation and maximum likelihood rotation (MLR) were used (see Appendix 2 for the ESEM input syntax; De Beer \& Van Zyl, 2019):

The fit of the two models was investigated using various Mplus fit statistics:

1. Absolute fit indices included the $\chi^{2}$ statistic, the root mean square error of approximation (RMSEA; values $\leq 0.05$ are acceptable) and standardised root mean square residual (SRMR; values $\leq 0.10$ are acceptable).

2. An incremental fit index, namely, the Tucker-Lewis Index (TLI; values $\geq 0.90$ are acceptable), and the Comparative Fit Index (CFI; values $\geq 0.95$ are acceptable) (Cangur \& Ercan, 2015; Hair, Black, Babin, \& Anderson, 2010; Hu \& Bentler, 1999; Yu, 2002).

3.The data was analysed at facet-level as it has an increased likelihood of cross-cultural replication and can be better used in future research.
The $\chi^{2}$ statistic is generally investigated to allow the researcher to assess the existence of any discrepancies between the model and observed covariance matrices and the magnitude of one discrepancy (Hu \& Bentler, 1999). Wheaton, Muthen, Alwin, and Summer (1997) recommend that $\chi^{2} / \mathrm{df}$ should be smaller than for an acceptable fit. However, Markland (2007) noted that in certain instances the $\chi^{2}$ test could be ignored. Markland (2007) stated that the $\chi^{2}$ test tends to be hypercritical when used within large sample sizes and in such cases will easily identify misfit. Furthermore, in an attempt to modify or respecify the model or its underlying theory, it may amount to fishing for significant results since '... such model modifications based on observed discrepancies might be capitalizing on chance sampling fluctuations in the data, improving fit at the expense of theoretical meaningfulness' (Markland, 2007, p. 865). Therefore, the researchers decided to consider the $\chi^{2}$ with prudence because the current study obtained a very large sample size and the researchers decided not to modify the model or its fundamental theory.

The RMSEA was inspected to indicate how well the model, with unknown but optimally chosen parameter estimates, would fit the populations' covariance matrix (Byrne, 1998). The SRMR was inspected to determine the average of standardised residuals between the observed and the hypothesised covariance matrices (Chen, 2007). The TLI, also referred to as a relative fit index, compares the $\chi^{2}$ indices for the models tested to a null model, a model indicating that all measured variables are uncorrelated and that the $\chi^{2}$ indices are very large (Bentler, 1990). The CFI compares the sample covariance matrix with the null model, which assumes that all latent variables are uncorrelated (Hooper, Coughlan, \& Mullen 2008).

When inspecting the factor loadings of the facets, loadings $\geq 0.30$ were deemed acceptable and representative of the respective factors (Brace, Kemp, \& Snelgar, 2009). The correlations between the SAPI factors were obtained on the factor level. The correlations between the SAPI factors with correlations having values $>0.10$ were said to display small effect sizes, correlations having values $>0.30$ indicated medium effect sizes, and correlations having values $>0.50$ showed large effect sizes (Cohen, 1988, 1992). The reliability of the factors was calculated using Cronbach's alpha $(\alpha)$ and McDonald's omega $(\omega)$ coefficients.

\section{Ethical consideration}

Ethical clearance for the study was granted by the Department of Industrial Psychology and People Management (IPPM) Research Ethics Committee, at the University of Johannesburg, South Africa.

\section{Results}

The descriptive statistics for the SAPI scales are presented in Table 2.

Table 2 indicates that the means (standard deviation [SD]) for the positively worded facets ranged between 3.58 (0.72) 
and 4.35 (0.42); the participants therefore mainly selected the 'Agree' response scale when answering these items. The means (SD) for the negatively worded facets ranged between $2.02(0.63)$ and $2.95(0.66)$; the participants therefore predominantly selected the 'Disagree' response scale when answering these items. The SDs were following the 99\% confidence level set to test for statistical significance. All SD values showed the scores obtained by the extended sample to be close to the mean, with limited differences between the participants. The skewness and kurtosis of each of the facets were satisfactory, as only factors with skewness of $>|2|$ and kurtosis of $>4$ are deemed unsatisfactory and unsuitable for factor analysis (Field \& Miles, 2010); therefore, all the facets were included in the analyses.

Table 3 reflects the goodness-of-fit indices as produced by the different analysis methods. Combining the results allowed the researchers to draw direct comparisons between the methods and to identify noteworthy results easily.

The CFA results show that the SAPI model did not fit the observed data produced by the measuring instrument $\left(\chi^{2}=7170.946 ; d f=154 ; \chi^{2} / d f=46.56 ; \mathrm{CFI}=0.827 ; \mathrm{TLI}=0.786\right)$, implying that the researchers would have to modify the

TABLE 2: Descriptive statistics of the South African Personality Inventory $(N=3912)$.

\begin{tabular}{|c|c|c|c|c|}
\hline Factor & $M$ & SD & Skewness & Kurtosis \\
\hline \multicolumn{5}{|l|}{ Conscientiousness } \\
\hline Achievement oriented & 4.04 & 0.51 & -0.45 & 0.45 \\
\hline Orderliness & 3.98 & 0.50 & -0.34 & 0.50 \\
\hline Traditionalism-religiosity & 3.62 & 0.84 & -0.73 & 0.17 \\
\hline \multicolumn{5}{|l|}{ Extraversion } \\
\hline Playfulness & 3.71 & 0.66 & -0.37 & 0.13 \\
\hline Sociability & 3.58 & 0.72 & -0.37 & -0.08 \\
\hline \multicolumn{5}{|l|}{ Neuroticism } \\
\hline Emotional balance & 3.88 & 0.54 & -0.59 & 0.96 \\
\hline Negative emotionality & 2.95 & 0.66 & 0.12 & -0.31 \\
\hline \multicolumn{5}{|l|}{ Openness } \\
\hline Broadmindedness & 4.00 & 0.55 & -0.46 & 0.32 \\
\hline Epistemic curiosity & 4.35 & 0.42 & -0.40 & 0.40 \\
\hline Intellect & 3.95 & 0.44 & -0.27 & 1.10 \\
\hline \multicolumn{5}{|c|}{ Positive social-relational disposition } \\
\hline Empathy & 4.03 & 0.49 & -0.35 & 0.76 \\
\hline Facilitation & 3.80 & 0.55 & -0.28 & 0.40 \\
\hline Integrity & 4.16 & 0.40 & -1.16 & 0.75 \\
\hline Interrelatedness & 3.94 & 0.44 & -0.24 & 0.87 \\
\hline Social intelligence & 3.94 & 0.56 & -0.52 & 1.25 \\
\hline Warm-heartedness & 4.03 & 0.44 & -0.22 & 0.68 \\
\hline \multicolumn{5}{|c|}{ Negative social-relational disposition } \\
\hline Arrogance & 2.02 & 0.63 & 0.63 & 0.55 \\
\hline Conflict seeking & 2.11 & 0.57 & 0.40 & 0.23 \\
\hline Deceitfulness & 2.21 & 0.60 & 0.44 & 0.40 \\
\hline Hostility or egoism & 2.13 & 0.50 & 0.45 & 0.40 \\
\hline
\end{tabular}

SD, standard deviation. instrument to get a good fit. In additional, the CFA results indicate that the SAPI model does not fit the population in focus (RMSEA $=0.108$ ) and question whether the model can be applied to the broader society within South Africa. The results obtained through the preliminary CFA analysis are therefore unsatisfactory and highlight the necessity of ESEM as an alternative method of analysis.

The ESEM results yielded more satisfactory results, with both the CFI and TLI increasing substantially $\left(\chi^{2}=1353.034\right.$; $d f=85 ; \chi^{2} / d f=15.92 ; \mathrm{CFI}=0.975 ; \mathrm{TLI}=0.944 ; \mathrm{RMSEA}=0.062$ ) because of cross-loadings being allowed within the ESEM model, thus indicating a better fit between the conceptual and observed data found in the SAPI measuring instrument. The decrease in RMSEA further indicates that, with ESEM, the SAPI model is a better fit to the data compared to the more restricted CFA model. This is also substantiated by the AIC and BIC values for the models, which show that the ESEM model was the better-fitting model.

Next, the parameter estimates of the ESEM analysis were used to inspect the general factors of personality, as explained by the variance of each facet within the SAPI model. The cross-loadings are reported because the ESEM analysis allows for the latent variables in the model to correlate with each other.

The results (Table 4$)$ reflect modest factor loadings $(\lambda=0.48$ $0.93)$ for the majority of the facets. Traditionalism-religiosity $(\lambda=0.26)$ displayed a poor factor loading on its expected factor but had a stronger significant loading social-relational positive $(\lambda=0.32)$. Most of the facets further displayed significant cross-loadings $<0.30$, with all the other SAPI factors. Integrity, as expected, loaded on both conscientiousness $(\lambda=0.30)$ and social-relational positive $(\lambda=0.38)$.

The researchers can determine the facets most representative of the SAPI factor they load onto when looking at each factor individually. In the conscientiousness factor, orderliness yielded the highest loading $(\lambda=0.88)$ and traditionalismreligiosity the lowest $(\lambda=0.26)$. Sociability yielded a high factor loading $(\lambda=0.92)$ on extraversion. In the opennessfactor, epistemic curiosity proved to have the highest factor loading $(\lambda=0.84)$. Negative emotionality presented a high loading $(\lambda=0.84)$ on the neuroticism, while emotional balance yielded an average, yet negative loading $(\lambda=-0.55)$. In the positive social-relational disposition factor, warmheartedness $(\lambda=0.93)$ displayed a high loading. All the facets within negative social-relational disposition yielded high factor loadings, with hostility-egoism demonstrating the average to highest factor loading $(\lambda=0.86)$, indicating that this factor is well defined by its facets.

TABLE 3: Summary of combined goodness-of-fit statistics for the various South African Personality Inventory models.

\begin{tabular}{lccccccccc}
\hline Method of analysis & $\chi^{2}$ & $d f$ & $\chi^{2} / d f$ & CFI & TLI & RMSEA & SRMR & AIC & BIC \\
\hline CFA & 7170.946 & 154 & 46.56 & 0.827 & 0.786 & 0.108 & 0.082 & 83330 & 83807 \\
ESEM & 1353.034 & 85 & 15.92 & 0.975 & 0.944 & 0.062 & 0.014 & 73683 & 74542 \\
\hline
\end{tabular}

$d f$, degrees of freedom; CFI, Comparative Fit Index; TLI, Tucker-Lewis Index; RMSEA, root mean square error of approximation; SRMR, standardised root mean square residual; CFA, confirmatory factor analysis; ESEM, exploratory structural equation modelling. 
TABLE 4: Parameter estimates of the South African Personality Inventory based on the exploratory structural equation modelling analysis.

\begin{tabular}{|c|c|c|c|c|c|c|c|}
\hline \multirow[t]{2}{*}{ Variable } & \multicolumn{6}{|c|}{$\lambda$} & \multirow[t]{2}{*}{$\delta$} \\
\hline & C & $\mathbf{E}$ & 0 & $\mathbf{N}$ & SRN & SRP & \\
\hline \multicolumn{8}{|l|}{ Conscientiousness } \\
\hline Achievement orientation & $0.60 * *$ & $0.07^{* *}$ & $0.23 * *$ & $-0.12 * *$ & $0.03 *$ & $0.07 * *$ & $0.29 * *$ \\
\hline Orderliness & $0.88^{* *}$ & -0.02 & 0.00 & $0.12 * *$ & $-0.09 * *$ & 0.00 & $0.26 * *$ \\
\hline Traditionalism-religiosity & $0.26^{* *}$ & $0.15^{* *}$ & $-0.17 * *$ & $0.06 * *$ & $-0.07 * *$ & $0.32 * *$ & $0.75 * *$ \\
\hline Integrity & $0.30 * *$ & $-0.04 *$ & $0.15 * *$ & 0.01 & $-0.27 * *$ & $0.38 * *$ & $0.34 * *$ \\
\hline \multicolumn{8}{|l|}{ Extraversion } \\
\hline Playfulness & $-0.08 * *$ & $0.60 * *$ & $0.19 * *$ & $0.06 * *$ & $0.07^{* *}$ & $0.08 * *$ & $0.48 * *$ \\
\hline Sociability & $0.10 * *$ & $0.92 * *$ & $-0.03 *$ & -0.01 & $-0.07 * *$ & -0.02 & $0.15^{* *}$ \\
\hline \multicolumn{8}{|l|}{ Openness } \\
\hline Broad-mindedness & $-0.12 * *$ & $0.17^{* *}$ & $0.76 * *$ & 0.02 & 0.02 & 0.02 & $0.37 * *$ \\
\hline Epistemic curiosity & $0.03 *$ & $-0.07 * *$ & $0.84 * *$ & $0.09 * *$ & $-0.11 * *$ & -0.01 & $0.34 * *$ \\
\hline Intellect & $0.23 * *$ & $0.05^{* *}$ & $0.48 * *$ & $-0.24 * *$ & $0.14 * *$ & $0.18^{* *}$ & $0.27 * *$ \\
\hline \multicolumn{8}{|l|}{ Neuroticism } \\
\hline Negative emotionality & $0.08^{* *}$ & -0.01 & 0.01 & $0.84 * *$ & $0.26 * *$ & $0.08^{* *}$ & $0.22 * *$ \\
\hline \multicolumn{8}{|l|}{ Social-relational negative } \\
\hline Arrogance & $0.12 * *$ & 0.03 & 0.00 & $-0.09 * *$ & $0.76 * *$ & $-0.14 * *$ & $0.41 * *$ \\
\hline Deceitfulness & $-0.23 * *$ & $-0.14 * *$ & 0.01 & $0.22 * *$ & $0.58 * *$ & $0.07 * *$ & $0.39 * *$ \\
\hline Conflict seeking & $-0.06 * *$ & $0.09 * *$ & $-0.06 * *$ & $0.09 * *$ & $0.77 * *$ & $0.03 *$ & $0.34 * *$ \\
\hline Hostility and egoism & $0.02 *$ & $-0.03 *$ & 0.01 & $0.09 * *$ & $0.86 * *$ & $-0.10 * *$ & $0.15^{* *}$ \\
\hline \multicolumn{8}{|l|}{ Social-relational positive } \\
\hline Integrity & $0.30 * *$ & $-0.04 *$ & $0.15^{* *}$ & 0.01 & $-0.27 * *$ & $0.38 * *$ & $0.34 * *$ \\
\hline Facilitation & $0.12 * *$ & $-0.05 *$ & $0.03 *$ & $-0.25 * *$ & $0.22 * *$ & $0.75 \% *$ & $0.30 * *$ \\
\hline Empathy & $-0.08 * *$ & $-0.04 *$ & $0.04 *$ & $0.29 * *$ & $-0.15^{* *}$ & $0.80 * *$ & $0.32 * *$ \\
\hline Social intelligence & $-0.03 *$ & $0.25 * *$ & 0.01 & $-0.03 * *$ & 0.01 & $0.64 * *$ & $0.36 * *$ \\
\hline Interpersonal relatedness & $-0.06 * *$ & $0.04 *$ & $0.03 *$ & $-0.16 * *$ & $-0.04 * *$ & $0.79 * *$ & $0.26 * *$ \\
\hline Warm-heartedness & 0.02 & $-0.02 *$ & $-0.02 *$ & $0.06 * *$ & $-0.04 * *$ & $0.93 * *$ & $0.16 * *$ \\
\hline
\end{tabular}

$\lambda$, factor loading; $\delta$, item uniqueness; $C$, conscientiousness; E, extraversion; O, openness; $N$, neuroticism; SRN, social-relational negative; SRP, social-relational positive; Targeted factor loadings are in bold. Reversed scored facets are italicised.

$*, p<0.05 ;{ }^{* *}, p<0.001$.

TABLE 5: Correlations coefficients of the South African Personality Inventory factors.

\begin{tabular}{|c|c|c|c|c|c|c|c|}
\hline Factor & $\alpha$ & $\omega$ & 1 & 2 & 3 & 4 & 5 \\
\hline 1. Conscientiousness & 0.78 & 0.78 & 1.00 & - & - & - & - \\
\hline 2. Extraversion & 0.75 & 0.76 & $0.19 *$ & 1.00 & - & - & - \\
\hline 3. Openness & 0.78 & 0.80 & $0.47 *$ & $0.39 *$ & 1.00 & - & - \\
\hline 4. Neuroticism & 0.70 & 0.73 & $-0.41 *$ & $-0.21 *$ & $-0.31 *$ & 1.00 & - \\
\hline 5. Positive social-relational disposition & 0.89 & 0.90 & $0.48 *$ & $0.58 *$ & $0.57 *$ & $-0.18^{*}$ & 1.00 \\
\hline 6. Negative social-relational disposition & 0.85 & 0.86 & $-0.31 *$ & -0.02 & $-0.13 *$ & $0.22 *$ & $-0.38 *$ \\
\hline
\end{tabular}

*, Correlation is significant at the 0.05 level (2-tailed).

Next, the factor correlations were inspected to determine the extent to which the six factors within the SAPI correlate with one another.

As shown in Table 5, which displays the correlation coefficients between the SAPI factors, the correlation between the socialrelational negative and extraversion factors was the only non-significant correlation. Social-relational positive and extraversion ( $r=0.58$; large effect size) and social-relational positive and openness $(r=0.57$; large effect size) produced the highest correlation coefficients. Furthermore, in terms of discriminant validity all of the correlations between the variables were far below the guideline of 0.85 (Brown, 2015), which would indicate problematic overlap of variance.

Table 5 further reflects the reliability coefficients of the respective SAPI factors. Both the Cronbach's $\alpha$ ranged between 0.70 and 0.89 , indicating acceptable levels of internal consistency for the factors (Nunnally \& Bernstein, 1994).
Similarly, the $\omega$ values ranged between 0.73 and 0.90 , indicating the acceptable reliability generated by the facets with regard to their associated factors

\section{Discussion}

The focus of this study was to assess the model-fit of the postulated SAPI model. Two different approaches were used to analyse the data, with each approach displaying varying results. The initial CFA analysis did not yield satisfactory results, resulting in a conclusion that the respective methods of analysis is not adequate for the intended analysis on the SAPI. The CFA thus provided insufficient support for the SAPI model previously established through EFA (Asparouhov \& Muthén, 2009; Marsh et al., 2014), indicating that the SAPI does not meet the criteria associated with model-fit (Marsh et al., 2010). The unsatisfactory results obtained through CFA can be ascribed to the inherent zero-loading requirement of the method (Marsh et al., 2010; Marsh et al., 2014). 
Consequently, an ESEM analysis was applied to obtain a more accurate understanding of the confirmed hypothesised SAPI model (Asparouhov \& Muthén, 2009; Marsh et al., 2014).

The ESEM analysis indicated a better, more suitable fit of the SAPI model, addressing questions regarding the broad applicability (Marsh et al., 2010) of the SAPI that were not accounted for during CFA, and evident in the findings of Mouton (2017). The satisfactory results obtained through ESEM indicate that the six factors underpinning the SAPI model can be used to explain the personality characteristics, with accompanying behaviours, exhibited most often within the South African sphere.

With model-fit obtained, it was necessary to inspect the parameter estimates to investigate the internal structure of the psychological model and compare the current results with those found by Fetvadjiev et al. (2015). The investigation involved the factor loadings of the facets representing the six SAPI factors. Each of the six SAPI factors had both highloading and low-loading facets, presenting noteworthy descriptions of personality in South Africa. Furthermore, the results obtained confirmed the findings of Fetvadjiev et al. (2015), with minor exceptions. The higher factor loadings obtained in this study indicate that all of the SAPI factors were better represented by their respective facets, except for conscientiousness that had two facets with lower factor loadings. The high factor loadings indicate that the facets and their respective items in the measuring instrument accurately describe personality in the South African sphere and that individuals find it easy to relate to the items and identify the associating behaviours while completing the questionnaire.

With regard to the conscientiousness factor, traits of being organised, punctual, precise, and thorough in everything one does, as well as being motivated and hard-working to achieve goals, are mostly associated with being conscientious (Bergh, 2013). The noticeably low factor loading of the traditionalism-religiosity facet implies that upholding traditions do not account for individuals striving to complete tasks and adhering to deadlines, confirming the empirical findings of Fetvadjiev et al. (2015) and contrasting previous theoretical postulations by $\mathrm{Nel}$ et al. (2012). The limited representativeness of traditionalism-religiosity can further be ascribed to the facet containing only a few items, having reliability coefficients that were low and not being suitable for cross-validation (see Fetvadjiev et al., 2015). However, the traditionalism-religiosity facet produced a higher loading onto the social-relational positive factor which is discussed further below.

With regard to the integrity facet, Fetvadjiev et al. (2015) found that integrity had a notable and equally strong double loading on both the conscientiousness and social-relational positive factors. Given the similar factor loadings on both factors, Fetvadjiev et al. (2015) postulated that there might be an underlying 'norm-driven, effortful self-regulation' (p. 4) communality between an individual's level of conscientiousness and the extent to which such an individual engages in positive interpersonal contexts. The remainder of the social-relational positive facets represents the factor very well, along with the cross-loading of the traditionalismreligiosity facet, possibly indicating that being respectful towards one's own culture could aid in maintaining good relationships with others.

The extraversion, openness, neuroticism and social-relational negative factors also seem to be well represented by their facets because most of their loadings were slightly higher than those presented by Fetvadjiev et al. (2015). The higher factor loadings are indicative of the theoretical model being well represented by the empirical data and that, at item level, personality is similarly perceived and described by individuals in South Africa. The strong loadings confirm the initial findings of $\mathrm{Nel} \mathrm{(2008)}$ ) and later confirmation by Valchev et al. (2014) of the South African context present personality factors in addition to those found within the Big Five model.

The correlations further yielded results similar to those found by Fetvadjiev et al. (2015). Social-relational negative and extraversion did not produce significant correlations, suggesting opposing theoretical frameworks for each factor. Extraversion is said to resemble behaviours aimed at being sociable and communicating openly with others (Nel, 2008), while social-relational negative relates to deceptive and hostile behaviour, causing one to move away from social interactions (Valchev et al., 2014). The medium-to-high correlations existing between social-relational positive and conscientiousness, and extraversion, respectively, are also confirmatory of previous research conducted on the social-relational influence on personality in South Africa (see Valchev et al., 2012; Valchev et al., 2014). The strong relationship between social-relational positive and conscientiousness can be a direct result of the strong presence of the integrity facet, indicating that dependability, loyalty, and honesty are needed to uphold relationships and obtain high achievements in life (Fetvadjiev et al. 2015; JensenCampbell, Knack, Waldrip, \& Campbell, 2007). Emphasising interpersonal relationships and positively managing them can further be ascribed to individuals enjoying being surrounded by people and engaging socially (Bergh, 2013). The correlations in this study also provide evidence for a strong relationship between social-relational positive and openness, corroborating the postulation of Fetvadjiev at al. (2015) that assessing openness outside the FFM allows for the openness facets to correlate with the broad factor of social-relatedness.

The representativeness of the social-relational factors evident in the results is further enhanced by the high reliability coefficients obtained for these factors, confirming the findings of Valchev et al. (2012), Valchev et al. (2014), and Fetvadjiev et al. (2015). Having higher alpha scores than the remaining 
four factors highlights the internal consistency of the test items and perhaps the uniqueness of personality in South Africa, and the replicability of the factors to the overall population in South Africa. Thus, individuals in the multicultural context are oriented towards building and fostering relationships with others, irrespective of the relationships starting controversially. The acceptable levels of consistency found in the conscientiousness, extraversion, openness and neuroticism factors confirm the findings of Fetvadjiev et al. (2015) that these SAPI factors correspond with the FFM and highlight the universality of the FFM found by McCrae and Costa (1997).

\section{Conclusion}

The overall results were deemed satisfactory and answered all of the research questions of the study. The results added to the progress of establishing a personality measure that encapsulates personality traits exhibited in a multi-cultural context. The model-fit and estimates obtained increased the confidence with which the SAPI can be applied to the broader society within South Africa and the generalisability of the personality traits to individuals from all 11 official cultural groups.

This study provided insight into the dynamics of personality within South Africa, with the ESEM application and the indicated cross-loadings; different personality facets may have a contribution to factors in reality that is not captured by regular CFA. Although the SAPI aligns with the FFM, personality within the South African context can only be fully understood through how relationships are formed, maintained and nurtured.

However, some limitations prevented more detailed results were obtained. Firstly, no control variables were added to the modelling. Secondly, the traditionalism-religiosity facet in the conscientiousness factor only consisting of three items and underperforming in the analyses, brought the relevance of this facet into question. Therefore, the underperforming facet should be redefined and possibly extended by developing additional items or adding those already existing in the SAPI item bank. Furthermore, based on the large data set and complexity of the SAPI, it is recommended that Bayesian Structural Equation Modeling (BSEM) be used to further consider the results obtained, as BSEM is not limited by the rotation method one selects and can produce a more detailed factor pattern (Xiao et al., 2019).

\section{Dedication}

The authors would like to dedicate this article in honour of two colleagues: Prof. Fons van de Vijver who sadly passed away on the 01 June 2019 while this article was under review. The authors would also like to dedicate this article in honour of Prof. Deon Meiring who passed away on 04 October 2019. Both men made substantial contributions to not only the SAPI-project, but also in the lives of others. Rest in peace.

\section{Acknowledgements}

This article was partially based on and part of the first author's PhD thesis. The authors thank the following people for their input and guidance with regard to the current article: Prof. Fons van de Vijver and Dr Velichko Fetvadjiev.

\section{Competing interests}

The authors have declared that no competing interests exist.

\section{Authors' contributions}

N.M. was the lead author, wrote up the article and was responsible for data collection. C.H. was the main postgraduate supervisor of the lead author, analysed the data and provided editorial input. D.M. gave conceptual guidance and provided editorial input and provided the SAPI data. L.T.d.B. performed with the statistical analyses and provided editorial input.

\section{Funding information}

This study was supported by the National Research Foundation (NRF), Grant No. (111764). The conclusions derived and opinions expressed are those of the authors and should not be ascribed to the NRF.

\section{Data availability statement}

The data are the intellectual property of the South African Personality Inventory Project and not for sharing.

\section{Disclaimer}

The views and opinions expressed in this article are those of the authors and do not necessarily reflect the official policy or position of any affiliated agency of the authors.

\section{References}

Asparouhov, T., \& Muthén, B. (2009). Exploratory structural equation modeling Structural Equation Modeling, 16, 397-438. https://doi.org/10.1080/107055 10903008204

Bentler, P.M. (1990). Comparative fit indices in structural models, Psychological Bulletin, 107(2), 238-246. https://doi.org/10.1037//0033-2909.107.2.238

Bergh, Z. (2013). The nature of personality and fundamental assumptions in personality study. In Z. Bergh and D. Geldenhuys (Eds.), Psychology in the work context (5th edn., pp. 290-314). Cape Town, SA: Oxford University Press.

Blokland, L.M.E. (2016). Non-Western (African) views of psychological constructs: Current context of psychological assessment in South Africa. In R. Ferreira (Ed.), Psychological Assessment: Thinking innovatively in the contexts of diversity (pp. 37-51). Cape Town: Juta and Company (Pty) Ltd.

Brace, N., Kemp, R., \& Snelgar, R. (2009). SPSS for psychologists. Houndmills, Basingstoke: Palgrave Macmillian.

Brown, T.A. (2015). Confirmatory factor analysis for applied research (2nd edn.). New York: Guilford Press.

Byrne, B.M. (1998). Structural Equation Modeling with LISREL, PRELIS and SIMPLIS: Basic concepts, applications and programming. Mahwah, NJ: Lawrence Erlbaum Associates.

Cangur, S., \& Ercan, I. (2015). Comparison of model fit indices used in structural equation modeling under multivariate normality. Journal of Modern Applied Statistical Methods, 14(1), 14. https://doi.org/10.22237/jmasm/1430453580

Chen, F.F. (2007). Sensitivity of goodness of fit indexes to lack of measurement invariance. Structural Equation Modeling, 14, 464-504. https://doi.org/10.1080/ 10705510701301834

Cheung, F.M. (2012). Mainstreaming culture in personality. American Psychologist, 67(8), 721-730. https://doi.org/10.1037/a0029876 
Cheung, F.M., Van de Vijver, F.J.R., \& Leong, F.T.L. (2011). Toward a new approach to the study of personality in culture. American Psychologist, 66(7), 593-603. https://doi.org/10.1037/a0022389

Church, A.T., \& Burke, P.J. (1994). Exploratory and confirmatory tests of the Big Five and Tellegen's three- and four-dimensional models. Journal of Personality and Social Psychology, 66, 93-114. https://doi.org/10.1037/0022-3514.66.1.93

Cohen, J. (1988). Statistical power analysis for behavioural sciences (2nd edn.). Hillsdale, NJ: Erlbaum.

Cohen, J. (1992). Quantitative methods in psychology: A power primer. Psychological Bulletin, 112(1), 155-159. https://doi.org/10.1037/0033-2909.112.1.155

De Beer, L.T., \& Van Zyl, L.E. (2019). ESEM code generator for Mplus. Retrieved from https://doi.org/10.6084/m9.figshare.8320250

Fetvadjiev, V.H., Meiring, D., Van de Vijver, F.J.R., Nel, J.A., \& Hill, C. (2015). The South African Personality Inventory (SAPI): A culture-informed instrument for the country's main ethnocultural groups. Psychological Assessment, 27(3), 827-837. https://doi.org/10.1037/pas0000078

Field, A., \& Miles, J. (2010). Discovering statistics using SAS. London: Sage.

Hair, J.F., Black, W.C., Babin, B.J., \& Anderson, R.E. (2010). Multivariate data analysis: International version, Pearson, New Jersey.

Henrich, J., Heine, S.J., \& Norenzayan, A. (2010). The weirdest people in the world? Behavioral and brain sciences, 33(2-3), 61-83. https://doi.org/10.1017/ S0140525X0999152X

Hill, C., Nel, J.A., Van de Vijver, F.J.R., Meiring, D., Valchev, V.H., Adams, B.G., \& De Bruin, G.P. (2013). Developing and testing items for the South African Personality Inventory (SAPI). South African Journal of Industrial Psychology, 39(1), 1-13. https://doi.org/10.4102/sajip.v39i1.1122

Hooper, D., Coughlan, J., \& Mullen, M.R. (2008). Structural equation modeling: Guidelines for determining model fit. Electronic Journal of Business Research Methods, 6(1), 53-60.

Hu, L.T., \& Bentler, P.M. (1999). Cut-off criteria for fit indexes in covariance structure analysis: Conventional criteria versus new alternatives. Structural Equation Modeling, 6(1), 1-55. https://doi.org/10.1080/10705519909540118

Jensen-Campbell, L.A., Knack, J.M., Waldrip, A.M., \& Campbell, S.D. (2007). Do Big Five personality traits associated with self-control influence the regulation of anger and aggression? Journal of Research in Personality, 41(2), 403-424. https:// doi.org/10.1016/j.jrp.2006.05.001

Laher, S., \& Cockroft, K. (2014). Psychological assessment in post-apartheid South Africa: The way forward. South African Journal of Psychology, 44(3), 303-314. https://doi.org/10.1177/0081246314533634

Markland, D. (2007). The golden rule is that there are no golden rules: A commentary on Paul Barrett's recommendations for reporting model fit in structural equation modelling. Personality and Individual Differences, 42(5), 851-858. https://doi. org/10.1016/j.paid.2006.09.023

Marsh, H.W., Lüdtke, O., Muthén, B., Asparouhov, T, Morin, A.J.S., Tratwein, U., \& Nagengast, B. (2010). A new look at the Big Five Factor structure through Exploratory Structural Equation Modeling. Psychological Assessment, 22(3), 471-491. https://doi.org/10.1037/a0019227

Marsh, H.W., Morin, A.J.S., Parker, P.D., \& Kaur, G. (2014). Exploratory Structura Equation Modeling: An integration of the best features of Exploratory and Confirmatory Factor Analysis. Annual Review of Clinical Psychology, 10, 85-110. Confirmatory Factor Analysis. Annual Review of Clinical Psyc
https://doi.org/10.1146/annurev-clinpsy-032813-153700

Marsh, H.W., Nagengast, B., \& Morin, A.J.S. (2013). Measurement invariance of BigFive factors over the life span: ESEM tests of gender, age, plasticity, maturity, and
La Dolce Vita effect. Developmental Psychology, 49(6), 1194-1218. https://doi. La Dolce Vita effect. Deve
org/10.1037/a0026913

Marshall, M.N. (1996). Sampling for qualitative research. Family Practice - An International Journal, 13(6), 522-525. https://doi.org/10.1093/fampra/13.6.522

McCrae, R.R. (1996). Social consequences of experiential openness. Psychological Bulletin, 120(3), 323. https://doi.org/10.1037/0033-2909.120.3.323

McCrae, R.R., \& Costa, P.T. (1997). Personality trait structure as a human universal. American Psychologist, 52, 509-516. https://doi.org/10.1037//0003-066X. 52.5.509
Moletsane, M. (2016). Understanding the role of indigenous knowledge in psychological assessment and intervention in a multicultural South African context. In R Ferreira (Ed.), Psychological Assessment: Thinking innovatively in the context of diversity (pp. 20-36). Cape Town: Juta and Company (Pty) Ltd.

Morin, A.J.S., \& Marsh, H.W. (2013). Exploratory structural equation modeling. In G.R. Hancock, \& R.O. Mueller (Eds.). Structural equation modeling: A second course (2nd edn.). Charlotte, NC: Information Age Publishing, Inc.

Mouton, S. (2017). An investigation into the first and second-order factor structure of the South African Personality Inventory (SAPI). Unpublished master's thesis, Stellenbosch University, Stellenbosch, South Africa.

Muthén, B., \& Muthén, L. (1998-2017). Mplus user's guide (8th edn.). Los Angeles, CA Muthén \& Muthén.

$\mathrm{Nel}$, J.A. (2008). Uncovering personality dimensions in eleven different language groups in South Africa: An exploratory study. Unpublished doctoral thesis, NorthWest University, Potchefstroom Campus, Potchefstroom, South Africa.

Nel, J.A., Valchev, V.H., Rothmann, S., Van de Vijver, F.J.R., Meiring, D., \& De Bruin, G.P. (2012). Exploring the personality structure in the 11 languages of South Africa. Journal of Personality, 80, 915-948. https://doi.org/10.1111/j.1467-6494.2011.00751.x

Netemeyer, R.G., Bearden, W.O., \& Sharma, S. (2003). Scaling procedures: Issues and applications. Thousand Oaks, CA: Sage.

Nunnally, J.C., \& Bernstein, I.H. (1994). The assessment of reliability. Psychometric Theory, 3, 248-292.

Republic of South Africa. (1998). Employment Equity Act, 1998, Government Gazette 400 (19740), Cape Town, 19 October 1998, Retrieved from https://www.gov.za/ sites/default/files/gcis_document/201409/a55-980.pdf.

Retief, A. (1992). The cross-cultural utility of the SAPQ: Bias or fruitful differences? South African Journal of Psychology, 17, 202-207. https://doi.org/10.1177/ 008124639202200403

Strauss, M.E., \& Smith, G.T. (2009). Construct validity: Advances in theory and methodology. Annual Review of Clinical Psychology, 5, 1-25. https://doi.org/ 10.1146/annurev.clinpsy.032408.153639.

Taylor, T.R. (1987). Test bias: The roles and responsibilities of test user and test publisher. Johannesburg: National Institute for Personnel Research.

Taylor, T.R., \& Boeyens, J.C.A. (1991). A comparison of black and white responses to the South African Personality Questionnaire. Pretoria: Human Sciences Research Council.

Valchev, V.H., Van de Vijver, F.J.R., Nel, J.A., Rothmann, S., Meiring, D., \& De Bruin, G.P. (2011). Implicit personality conceptions of the Nguni cultural-linguistic group of South Africa. Cross-Cultural Research, 45, 235-266. https://doi.org/10.1177/ 1069397111402462

Valchev, V.H., Nel, J.A., Van de Vijver, F.J.R., Meiring, D., De Bruin, G.P., \& Rothmann, S. (2012). Similarities and differences in implicit personality concepts across ethnocultural groups in South Africa. Journal of Cross-Cultural Psychology, 44, 365-388. https://doi.org/10.1177/0022022112443856

Valchev, V.H., Van de Vijver, F.J.R., Nel, J.A., Rothman, S., \& Meiring, D. (2013). The use of traits and contextual information in free personality descriptions across ethnocultural groups in South Africa. Journal of Personality and Social Psychology, 104(6), 1077-1091. https://doi.org/10.1037/a0032276

Valchev, V.H., Van de Vijver, F.J.R., Meiring, D., Nel, J.A., Hill, C., Laher, S., \& Adams, B.G. (2014). Beyond agreeableness: Social-relational personality concepts from an indigenous and cross-cultural perspective. Journal of Research in Personality, 48(1), 17-32. https://doi.org/10.1016/j.jrp.2013.10.003

Van de Vijver, F., \& Leung, K. (2001). Personality in cultural context: Methodological issues. Journal of Personality, 69, 1007-1031. https://doi.org/10.1111/14676494.696173

Wheaton, B., Muthen, B., Alwin, D., F., \& Summers, G. (1977). Assessing reliability and stability in panel models, Sociological Methodology, 8(1), 84-136. https://doi. org/10.2307/270754

Xiao, Y., Liu, H., \& Hau, K. (2019). A comparison of CFA, ESEM, and BSEM in test structure analysis. Structural Equation Modeling: A Multidisciplinary Journal, 1-13. https://doi.org/10.1080/10705511.2018.1562928

Yu, C.Y. (2002). Evaluating cutoff criteria of model fit indices for latent variable models with binary and continuous outcomes (Vol. 30). Los Angeles, CA: University of California. 


\section{Appendix 1}

\section{Mplus syntax for confirmatory factor analysis (CFA)}

TITLE: SAPI CFA

DATA:

FILE IS data.txt;

VARIABLE:

NAMES ARE empathy integrity interrel socialintel warmheart arrogance confseek deceit hosego emobal-negem play-sociability achievement orderliness tradrel broadmind episcur intellect;

USEVARIABLES ARE ALL;

MISSING ARE ALL (-999);

ANALYSIS:

ESTIMATOR=MLR;

PROCESSORS $=8$;

STARTS=20;

MODEL:

POSRELD by

empathy-warmheart;

NEGRELD by

arrogance-hosego;

NEUROT by

emobal-negem;

EXTRA by

play-sociability;

CONSCIENCE by

achievement

orderliness

tradrel

integrity;

OPEN by

broadmind-intellect;

OUTPUT: stdyx; tech4; 


\section{Appendix 2}

\section{Mplus syntax for exploratory structural equation model}

TITLE: SAPI ESEM

!Generated with the ESEM code generator for Mplus (De Beer \& Van Zyl, 2019)

DATA:

FILE IS data.txt;

VARIABLE:

NAMES ARE empathy integrity interrel socialintel warmheart arrogance confseek deceit hosego emobal-negem play-sociability achievement orderliness tradrel broadmind episcur intellect;

USEVARIABLES ARE ALL;

MISSING ARE ALL (-999);

ANALYSIS:

ESTIMATOR=MLR;

PROCESSORS $=8$;

STARTS $=20$;

ROTATION=TARGET;

\section{MODEL:}

\section{POSRELD by}

empathy-warmheart arrogance-hosego 0

emobal-negem $\sim 0$

play-sociability 0

achievement-tradrel $\sim 0$

broadmind-intellect $0(* 1)$;

\section{NEGRELD by}

arrogance-hosego

empathy-warmheart $\sim 0$

emobal-negem $\sim 0$

play-sociability 0

achievement-tradrel $\sim 0$

broadmind-intellect $0(* 1)$;

\section{NEUROT by}

emobal-negem

empathy-warmheart $\sim 0$

arrogance-hosego 0

play-sociability 0

achievement-tradrel $\sim 0$

broadmind-intellect $0(* 1)$;

\section{EXTRA by}

play-sociability

emobal-negem $\sim 0$

empathy-warmheart $\sim 0$

arrogance-hosego 0

achievement-tradrel $\sim 0$

broadmind-intellect $0(* 1)$; 


\section{CONSCIENCE bY}

achievement-tradrel integrity

play-sociability 0

emobal-negem $\sim 0$

empathy-warmheart 0

arrogance-hosego 0

broadmind-intellect $0(* 1)$;

OPEN by

broadmind-intellect

achievement-tradrel 0

play-sociability 0

emobal-negem $\sim 0$

empathy-warmheart 0

arrogance-hosego $0(* 1)$;

OUTPUT: stdyx; tech4; 